\title{
Back "pane" secondary to glass coffee table mishap: case illustration
}

\author{
Rosalie Mercure-Cyr, MD, and Daryl R. Fourney, MD, FRCSC \\ Division of Neurosurgery, Royal University Hospital, University of Saskatchewan, Saskatoon, Saskatchewan, Canada
}

https://thejns.org/doi/abs/10.3171/2019.10.SPINE191208

KEYWORDS penetrating spine trauma; spinal cord injury; intradural injury; glass; CSF leak

$\mathrm{A}$ 47-YEAR-OLD male patient presented with a severe laceration of the right thoracolumbar junction after he fell backward onto a tempered glass coffee table. He had no neurologic symptoms or signs. A CT scan showed a wedge-shaped piece of glass that measured almost $7 \mathrm{~cm}$ penetrating the spinal canal at the T11-12 level, causing a rightward deviation of the spinal cord (Fig. 1).

The patient was taken to the operating room urgently for a T11-12 laminectomy under microscopic visualization performed with motorevoked potential monitoring. The glass fragment was removed gently along its original trajectory path. A durotomy due to the fragment was found to the left of midline just alongside the pedicle and was repaired with duraplasty.

This case demonstrates a very rare injury pattern, as the vast majority of intradural penetrating injuries result in complete or incomplete spinal cord injury due to a narrow subarachnoid space at the thoracic level. ${ }^{1,4}$ This patient remained neurologically intact postoperatively.

To our knowledge, this is the first case reported in the literature that describes a patient with an intradural thoracic glass injury without significant neurological deficits. The outcome in this case supports the already-existing evidence for successful management of a penetrating spine injury using microscopic techniques, intraoperative neurophysiologic monitoring, and dural repair. ${ }^{2,3}$

\section{References}

1. Komarowska M, Debek W, Wojnar JA, Hermano- wicz A, Rogalski M: Brown-Séquard syndrome in a 11-year-old girl due to penetrating glass injury to the thoracic spine. Eur J Orthop Surg Traumatol 23 (Suppl 1):S141-S143, 2013

2. Kumar A, Pandey PN, Ghani A, Jaiswal G: Penetrating spinal injuries and their management. J Craniovertebr Junction Spine 2:57-61, 2011

3. Morrow KD, Podet AG, Spinelli CP, Lasseigne LM, Crutcher CL, Wilson JD, et al: A case series of penetrating spinal trauma: comparisons to blunt trauma, surgical indications, and outcomes. Neurosurg Focus 46(3):E4, 2019

4. Müller H, Brock M, Pöll W, Fischer T: Injury to the thoracic spinal cord by glass fragments. Case report. Spine (Phila Pa 1976) 10:475-477, 1985

\section{Disclosures}

The authors report no conflict of interest concerning the materials or methods used in this study or the findings specified in this paper.

\section{Author Contributions}

Conception and design: Mercure-Cyr. Acquisition of data: Mercure-Cyr. Drafting the article: Mercure-Cyr. Critically revising the article: Fourney. Reviewed submitted version of manuscript: Fourney. Approved the final version of the manuscript on behalf of both authors: Fourney. Administrative/technical/material support: Mercure-Cyr.

\section{Supplemental Information \\ Previous Presentations}

This case has been previously presented in poster format at the 54th Canadian Neurological Sciences Federation, Montreal, Quebec, Canada, June 16-19, 2019. 

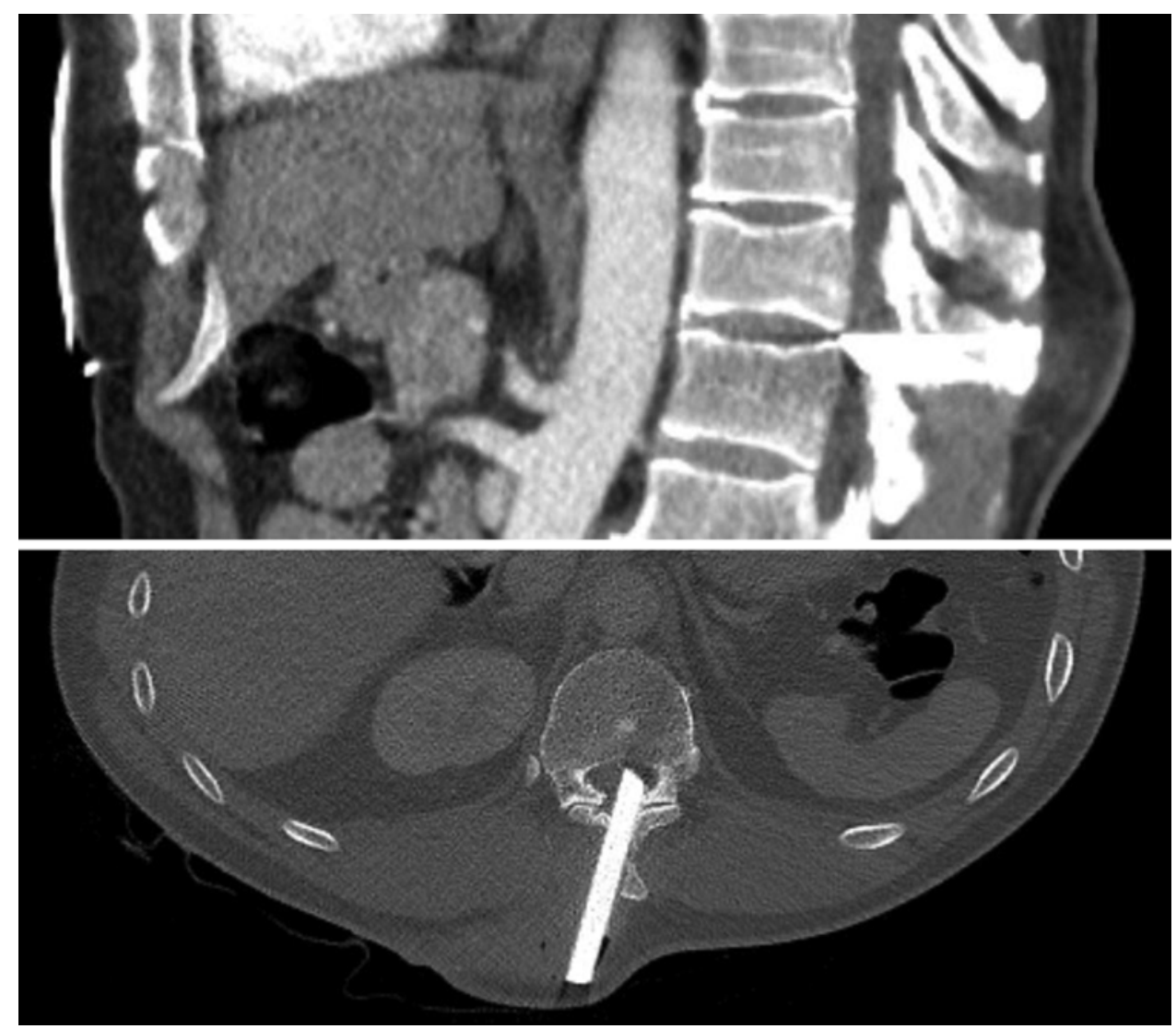

FIG. 1. Sagittal (upper) and axial (lower) CT scans showing penetrating glass through the spinal canal at the T11-12 level. 